\title{
Blue energy for sustainable water reclamation in WWTPs
}

\author{
Accepted Manuscript \\ Journal of Water Process Engineering
}

21 October 2019
L. Gómez-Coma, V.M. Ortiz-Martínez, M. Fallanza, A. Ortiz, R. Ibañez, I. Ortiz
Department of Chemical and Biomolecular Engineering. University of Cantabria, Av. Los Castros 46, 39005 Santander, Spain
*corresponding author: ortizi@unican.es

(C)2019 This manuscript version is made available under the CC-BY-NC-ND 4.0 license http://creativecommons.org/licenses/by-nc-nd/4.0/

The definitive publisher version is available online at https://doi.org/10.1016/j.jwpe.2019.101020 


\title{
Blue energy for sustainable water reclamation in WWTPs
}

\author{
L. Gómez-Coma, V.M. Ortiz-Martínez, M. Fallanza, A. Ortiz, R. Ibañez, I. Ortiz \\ Department of Chemical and Biomolecular Engineering. University of Cantabria, \\ Av. Los Castros 46, 39005 Santander, Spain \\ *corresponding author: ortizi@unican.es
}

\begin{abstract}
The benefits of wastewater (WW) reclamation to alleviate the stress of freshwater resources are counterbalanced by the required energy demand to drive the treatments. This handicap can be considerably minimized when renewable energy sources are integrated to perform this process, increasing the environmental and energy sustainability of the reclamation process. This work reports the assessment of a new strategy for WW reclamation in shoreline wastewater treatment plants (WWTPs) through the conversion of the salinity gradient energy (SGE) generated in the contact between reclaimed water (RW) and seawater (SW) to electricity by the use of reverse electrodialysis (RED). Secondary effluents from the selected WWTP were further treated by a simple remediation process consisting of coagulation-flocculation and solids removal, ending with a filtration stage; the obtained $\mathrm{RW}$ contained $0.008 \mathrm{M} \mathrm{NaCl}$ and was used as low concentrated solution in the RED stack; besides, filtered $\mathrm{SW}$ with $0.5 \mathrm{M} \mathrm{NaCl}$, was employed as high concentrated solution. The plant run for 480 hours, reaching gross power up to $1.43 \mathrm{~W} / \mathrm{m}^{2}$ without decay along the operation time indicating that no fouling issues appeared in this time period. This represents a great improvement in comparison to the results published in the literature so far; the slight increase in the salinity of RW still allowed for its further reuse. Thus, a novel and energy sustainable strategy to promote WW reclamation with simultaneous SGE recovery is presented.
\end{abstract}

Keywords: Wastewater reclamation; energy sustainability; salinity gradient power; reverse electrodialysis. 


\section{Introduction}

Water demands are continuously increasing to supply agriculture, industry and cities due to economic and population growth, while water availability is becoming heavily committed in many areas of the world. Nowadays, estimates suggest that about $33 \%$ of population live in water-stressed countries and this figure could be increased to $66 \%$ by 2025 [1]. In addition, the growing industrialization process leads to a rise in water demands, which is a challenge specially in water-scarce regions [2]. The use of reclaimed water (RW) can greatly contribute to the alleviation of the stress imposed on freshwater resources in areas of scarcity, promoting sustainability. This type of water can be employed towards multiple non-potable purposes such as agricultural irrigation, industrial use, urban greening, surface water recharge and even for domestic uses [3]. Water demands are continuously increasing to supply agriculture, industry and cities due to economic and population growth, while water availability is becoming heavily committed in many areas of the world. The use of RW can greatly contribute to the alleviation of the stress imposed on freshwater resources. This type of water can be employed for irrigation, industrial processing and even for domestic uses. Thus, recent works focus on transforming WW into RW is an environmental challenge since it promotes ecological protection by reducing the impact of discharges and allows water reuse $[4,5,2]$. Under this perspective, urban WW constitutes a valuable resource that, if sustainably managed, can be regarded as a central pillar of the circular economy $[6,7]$. In fact, Europe policies and directives are becoming stricter on the standards for WW discharges encouraging water reuse [8-11]. In contrast, running WWTPs imply high energy consumption, which is mainly supplied through fossil fuels, thus contributing negatively to climate change. Depending on the plant scale, units and treatment intensity, the typical energy consumption per $\mathrm{m}^{3}$ falls in the range $0.25-0.60 \mathrm{kWh} / \mathrm{m}^{3}$, causing the release of $0.276 \mathrm{KgCO}_{2} \mathrm{eq} / \mathrm{kWh}[12,13]$. Water reclamation would require additional energy consumption, which restricts its applicability in many cases despite being technically feasible. Thus new strategies, such as the promotion of self-sufficiency in WWTPs through the use of emerging renewable energy technologies, are necessary to perform this process in a sustainable way [14].

Salinity gradient energy (SGE) is created from the difference in salinity of two streams and represents a highly promising option as source of renewable energy. Considering the discharge of rivers into the sea, it would be possible to generate up to 2 TW of salinity- 
gradient power, while the discharge of treated WW effluents into the sea could provide another $18 \mathrm{GW}$ [15]. To this date, there are two available technologies to extract SGE: Pressure Retarded Osmosis (PRO) [16,17] and Reverse Electrodialysis (RED) is the most efficient technology to harness this type of energy, with no associated thermal or environmental pollution, and without causing greenhouse gas emissions. This technology employs stacks formed of alternate ion exchange membranes (cationic and anionic) separated by spacers to create compartments through which the solutions are fed [18]. The operation cost of SGE is estimated to be less than $0.08 € / \mathrm{kWh}$ (excluding any subsidy or compensation), comparable to that of wind energy [19] with the additional advantage that SGE can be generated continuously $24 \mathrm{~h}$ per day and 365 days a year, unlike wind or solar energy [20].

WWTPs have the challenge to boost reclamation of treated WW at the same time that fossil fuels based-energy consumption is reduced. In this sense, WWTPs located in coastal areas where SW can be used as high concentration stream to feed RED units are ideal frameworks for harvesting SGE. RED technology will be fed by SW on one inlet and by the treated secondary effluent, RW, on the second one. Power recovery from these streams can account for $0.63 \mathrm{~W} / \mathrm{m}^{2}$ per membrane pair installed [21]. In addition, the flowrate of the high concentration stream can be adapted to the available flowrate of WWTP discharges, in order to ensure its optimum exploitation.

Currently, the bottle-neck for water reclamation processes is the tradeoff between the adequate treatment to make possible the reuse of water and the minimization of energy consumption. In SGE-RED systems, the main problem associated with the use of biologically treated WW lies on the presence of divalent ions such as magnesium $\left(\mathrm{Mg}^{2+}\right)$, calcium $\left(\mathrm{Ca}^{2+}\right)$ and sulphate $\left(\mathrm{SO}_{4}{ }^{2-}\right)$ and particulate matter, which can affect membrane resistance or cause membrane fouling at medium- and long- term operation thus, lowering power performance [22-29]. However, working with RW would avoid these issues feeding the RED stack for internal energy recovery before end-use applications.

This work aims to demonstrate the viability of water reclamation at the same time that energy is recovered by SGE-RED technology, avoiding the typical fouling issues arising from its operation. A coastal plant was selected to facilitate the use of SW as high concentrated solution, whereas treated secondary effluents, RW, were employed as low concentrated solution. A simple reclamation treatment consisting of coagulation, flocculation and decantation stages followed by filtration to remove solids was applied to 
treat secondary WW. This stream was then continuously used for power generation over 480 hours in a RED stack. The reclamation treatment applied to the secondary effluent and the slight increase in salinity after the energy recovery step contributed to produce water with high enough quality for further reuse [30]. Thus, we underline the benefits of coupling the concepts and practice of WW reclamation and SGE harvesting to offer more sustainable strategies for water reclamation and reuse in coastal WWTPs.

\section{Materials and methods}

\subsection{Treatment for secondary WW effluent}

A secondary (biologically treated) WWTP effluent was subjected to a relatively simple treatment to increase water quality and allow further reuse as reclaimed water (RW) and, at the same time to meet the standards to feed the RED-SGE stack. This effluent was first characterized by an initial silt density index (SDI) of 76.28. This index is a measure for the fouling capacity of water and was determined according to the ASTM D4189-95 (2002) standard [29]. In addition, the initial turbidity of the WWTP effluent was as high as 6.72 NTUs, which exceeds the standard limits for reclaimed water. A trade-off between the intensity of the treatments applied to the secondary effluent and the water quality standards for further use needs to be found. This fact is motivated by the energy costs associated with treatment operations. Since a depth filtration implies high-energy consumption, a coagulation-flocculation process was employed in order to reduce the following critical parameters: SDI, turbidity, total suspended solids (TSS) and chemical oxygen demand (COD), which are indicators of water quality with restricted limits depending on water standards. Coagulation is commonly used prior to sedimentation in order to remove particles. Specifically, the process of coagulation neutralises charge and forms large flocs coming from finely divided particles. From its part, in flocculation processes, the colloids come out of the suspension due to the addition of a clarifying agent. The secondary effluent was first coagulated using aluminium sulphate (Acideka, Spain) at $265.0 \mathrm{mg} / \mathrm{L}$ and then flocculated with polyacrylamide (A.E. Vallés, Spain) at $2.0 \mathrm{mg} / \mathrm{L}$, followed by settling for $24 \mathrm{~h}$. Subsequently, filtration was performed using cartridge filters of up to $10 \mu \mathrm{m}$. Figure 1 summarises the treatment applied to the secondary WW stream. 


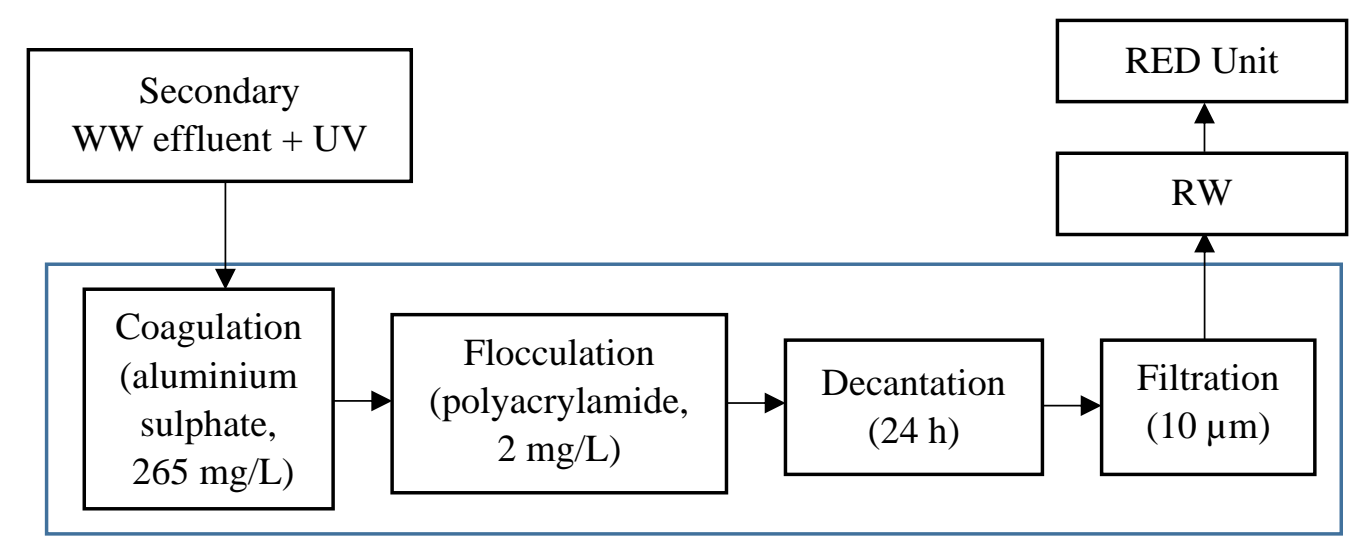

Figure 1. Treatment applied to the secondary WWTP to obtain RW.

For its part, seawater (SW) was treated with filters of $1 \mu \mathrm{m}$ to remove all the particulate matter from this stream. Afterwards, ultraviolet disinfection was applied. Figure 2, shows the scheme of the treatment.

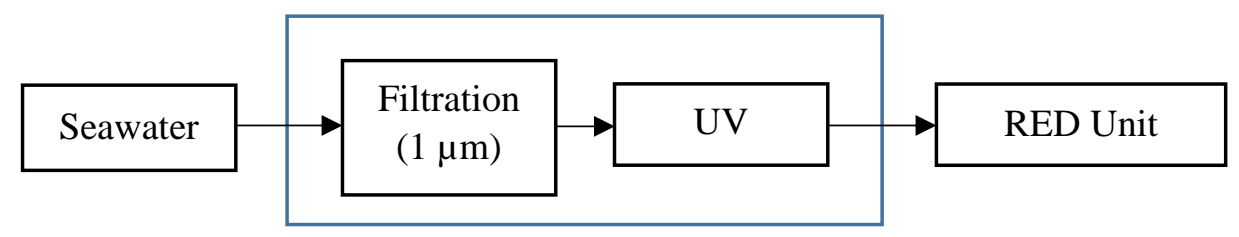

Figure 2. Treatment applied to SW.

As it will be discussed in the following section, the treatments applied to RW and SW effluents were suitable to avoid the fouling issues that different authors have previously reported when working with natural and waste streams to feed RED stacks [26,27,3133].

\subsection{SGE-RED experiments}

The SGE experiments were performed using a RED stack comprising 20 cell pairs formed by anion and cation exchange membranes (AEMs and CEMs, respectively) with commercial names FKS-50 and FAS-50, respectively, and supplied by Fumatech ${ }^{\circledR}$. Each membrane had $36 \mathrm{~cm}^{2}$ of area, $50 \mu \mathrm{m}$ of thickness and membranes were arranged alternately between commercial polyethersulfone spacers with a porosity of $82.5 \%$ (Fumatech®, Germany). AEMs and CEMs membranes were characterized by the permselectivity ranges of 0.92-0.96 and 0.97-0.99 for $\mathrm{KCl}$ concentrations between 0.1 
and $0.5 \mathrm{M}$, respectively. At the ends of the stack, an electrode rinse solution (ERS) composed of $0.05 \mathrm{M} \mathrm{K}_{3} \mathrm{Fe}(\mathrm{CN})_{6}, 0.05 \mathrm{M} \mathrm{K}_{4} \mathrm{Fe}(\mathrm{CN})_{6}$ (Scharlau, purity >99.0\%) and 0.25 $\mathrm{M} \mathrm{NaCl}$ (Fisher Chemicals, assay $>99.5 \%$ ) was continuously recirculated through the anodic and cathodic compartments to maintain electroneutrality by means of redox reactions.

RW coming from the process depicted in Figure 1 was used as LC solution while SW coming from the Cantabrian Sea (Spain) was used as HC solution after the treatment described in Figure 2.

The flowrates of RW and SW streams were $130 \mathrm{~mL} / \mathrm{min}$, equivalent to a linear velocity of $1.19 \mathrm{~cm} / \mathrm{s}$. These flowrates were selected to comply with the constraints of linear velocity of the stack $(1.0-2.0 \mathrm{~cm} / \mathrm{s})$. An electronic load was used to perform the experiments (Chroma Systems Solutions 63103A, USA).As previously reported in other works [18,21,34], RED performance is greatly influenced by temperature. To avoid the influence of this parameter during operation, the temperatures of the water streams were monitored and maintained constant at $24 \pm 1^{\circ} \mathrm{C}$. In addition, the stack was isolated for temperature control using a conventional oven at the same temperature. A schematic diagram of the experimental plant is shown in Figure 3.

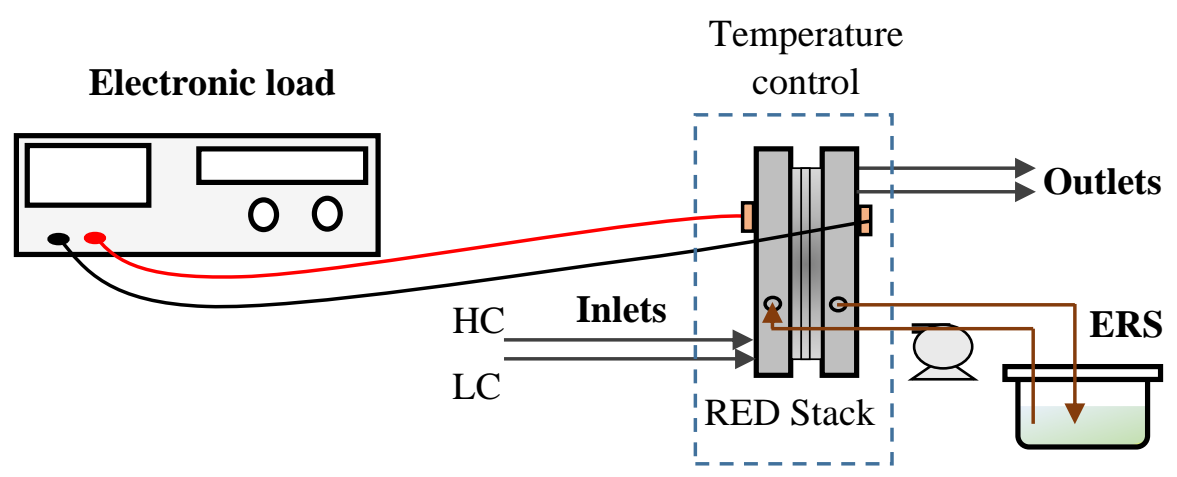

Figure 3. Schematic diagram of the experimental set-up.

A comprehensive mathematical model reported in a previous work [18] and developed in the software Aspen Custom Model V9 (AspenTech) was employed to predict the electrical performance of the RED stack under the above mentioned conditions. The response of the system in terms of open circuit voltage (OCV) and power output were selected to study the stability of the system over time and to detect any possible decay in performance due to the presence of membrane fouling. 


\section{Results and discussion}

In this section, the quality of the reclaimed water obtained with the proposed tertiary treatment is presented and discussed. In addition, the viability of the use of RW and LC as feed streams in SGE-RED technology is analysed. Finally, the results obtained with RED operation working with real water streams over 480 hours using SW and RW as HC and LC streams, respectively, are presented. The values achieved with the RED stack are compared with results already reported in the literature.

\subsection{Characterization of reclaimed water obtained from WWTP effluents}

The use of RW for urban, industrial or agricultural activities is becoming a goal worldwide due to the increasing water scarcity [10]. Nevertheless, in order to use WW effluents after treatment as RW, it is necessary to comply with the existing regulations. Specifically, EU directives as well as more restrictive policies on RW use in some European countries such as Spain set the maximum values for turbidity, total suspended solids (TSS) and chemical oxygen demand (COD) $[8,11,35]$.

According to the data shown in Table 1, the applied tertiary treatment described in Figure 1 comprising the stages of coagulation, flocculation, decantation and filtration, demonstrated to be adequate to obtain reclaimed water for different uses: Turbidity showed an important reduction from 6.72 before treatment to 0.4 NTU after the treatment (turbidity reduction higher than $94 \%$ ). In the case of TSS and COD, the values after treatment were $7.9 \mathrm{mg} / \mathrm{L}$ and $25 \mathrm{mg} / \mathrm{L}$ respectively. Moreover, the conductivity with a value of $1.8 \mathrm{mS} / \mathrm{cm}$, that increased after RW use in the SGE-RED plant, also met the requirements for RW (maximum limit of $3.0 \mathrm{mS} / \mathrm{cm}$ ). The obtained reclaimed waters fulfil the allowable concentration in the target parameters such as turbidity, TSS or conductivity for reuse in urban activities like garden, park and street irrigation, fire systems or industrial applications like process or cleaning water in industrial sectors other than the food industry $[6,34,9]$. Finally, total organic carbon (TOC), a non-specific indicator of water quality that measures the amount of carbon found in an organic compound, was reduced over $60 \%$. Thus, the treatment applied was suitable to reach the required quality of RW for multiple uses as mentioned before. Moreover, this treatment demonstrates the possibility of obtaining reclaimed water using SGE-RED technology without penalty cost associated to energy consumption after a simple tertiary treatment. 
Table 1. Main physicochemical parameters of water streams before and after treatment.

\begin{tabular}{|c|c|c|c|c|c|c|c|}
\hline & $\begin{array}{l}\text { Conductivity } \\
(\mathrm{mS} / \mathrm{cm})\end{array}$ & $\mathrm{pH}$ & $\begin{array}{c}\mathrm{COD} \\
\left(\mathrm{mg} / \mathrm{L} \mathrm{O}_{2}\right)\end{array}$ & $\mathrm{TSS}(\mathrm{mg} / \mathrm{L})$ & $\begin{array}{c}\text { TOC } \\
(\mathrm{mg} / \mathrm{L})\end{array}$ & $\begin{array}{l}\text { Turbidity } \\
\text { (NTU) }\end{array}$ & SDI \\
\hline $\begin{array}{c}\text { Secondary } \\
\text { WW } \\
\text { effluent }\end{array}$ & $0.661 \pm 0.172^{\mathrm{a}}$ & $<7.5^{\mathrm{a}}$ & $61.68 \pm 19.08^{\mathrm{a}}$ & $9.75 \pm 6.15^{\mathrm{a}}$ & $\begin{array}{c}12.02 \pm 8.03^{\mathrm{a}} \\
11^{\mathrm{b}}\end{array}$ & $\begin{array}{c}8.08 \pm 5.48^{\mathrm{a}} \\
\quad 6.72^{\mathrm{b}}\end{array}$ & 76.28 \\
\hline RW (LC) & 1.8 & $<7.5$ & 25 & 7.9 & 4.3 & 0.4 & 13.90 \\
\hline $\begin{array}{c}\text { SW } \\
\text { (before } \\
\text { treatment) }\end{array}$ & $52.3 \pm 2.2^{\mathrm{a}}$ & $<8.0^{\mathrm{a}}$ & $<200^{\mathrm{a}}$ & $\begin{array}{c}12.75 \pm 7.62^{\mathrm{a}} \\
28^{\mathrm{b}}\end{array}$ & $<10^{\mathrm{a}}$ & $4.17 \pm 3.20^{\mathrm{a}}$ & n.a. \\
\hline SW (HC) & 54.7 & $<8.0$ & $<200$ & $<5$ & 2 & 0.8 & n.a. \\
\hline
\end{tabular}

Moreover, the treatment applied to the secondary WW effluent to obtain RW was effective at greatly reducing both SDI and TOC. A decrease in SDI from an initial value of 76.28 down to 13.90 was achieved, implying a significant reduction of over $81 \%$ in this parameter. In the case of SW, after treatment, a reduction of $80 \%$ was obtained in turbidity as well as TSS, from initial values of 4 NTUs and $28 \mathrm{mg} / \mathrm{L}$, respectively. It was important to reduce these parameters in order to avoid the fouling issues when using SW as feeding stream in RED stacks.

After treatment, the concentrations of the main ions present in both streams were also measured as displayed in Table 2. As observed, the concentrations of sodium $\left(\mathrm{Na}^{+}\right)$in the $\mathrm{HC}$ and LC streams were $0.5 \mathrm{M}$ and $0.008 \mathrm{M}$, respectively, which correspond to the typical average values of the salt concentration in the Atlantic Ocean Sea and of the WWTP effluents. The divalent ion specie with highest concentration in the seawater was found to be magnesium, while in the case of the RW, magnesium and calcium were within the same ratio because the area in which the WWTP is located is characterized by a high presence of calcite. Nevertheless, the concentration of divalent ions in RW is lower than $20 \%$ with respect to $\mathrm{Na}^{+}$.

Table 2. Ion compositions of HC and LC streams (M).

\begin{tabular}{|c|c|c|c|c|}
\cline { 2 - 5 } \multicolumn{1}{c|}{} & $\mathrm{Na}^{+}$ & $\mathrm{Mg}^{2+}$ & $\mathrm{Ca}^{2+}$ & $\mathrm{SO}_{4}{ }^{2-}$ \\
\hline $\mathrm{SW}(\mathrm{HC})$ & 0.50 & 0.056 & 0.009 & 0.030 \\
\hline $\mathrm{RW}(\mathrm{LC})$ & 0.008 & 0.0014 & 0.0014 & 0.00026 \\
\hline
\end{tabular}




\subsection{Experimental determination of energy potential subtracted from the salinity gradient in a RED system using RW and SW}

In order to determine the potential energy that could be subtracted from the salinity gradient from the mixing of these two streams through RED technology, an assessment of model water streams composed by extra-pure $\mathrm{NaCl}, \mathrm{MgCl}_{2}, \mathrm{CaCl}_{2}$ and $\mathrm{Na}_{2} \mathrm{SO}_{4}$ in distilled water, taking into account the concentrations of SW and RW included in Table 2. First, an experiment using only $\mathrm{NaCl}$ was performed ( $\mathrm{SW}=0.5 \mathrm{M}, \mathrm{RW}=0.008 \mathrm{M})$ and later, the rest of salts were added. Figure 4 shows the gross power obtained as function of current density, with both parameters normalized to effective cell-pair membrane area. The values accomplished when pure $\mathrm{NaCl}$ was used are slightly higher $\left(1.6 \mathrm{~W} / \mathrm{m}^{2}\right)$ in comparison to the scenario in which the different divalent ions were added $\left(1.42 \mathrm{~W} / \mathrm{m}^{2}\right)$. These values are similar or higher than previous data reported in the literature [21]. The presence of $\mathrm{MgCl}_{2}$ and $\mathrm{CaCl}_{2}$ led to a drop in power output of only $10 \%$, while the addition of $\mathrm{Na}_{2} \mathrm{SO}_{4}$ did not further affect power performance. These results demonstrate the possibility of using SGE-RED in reclaimed water processes in order to favour the reduction in fossil fuel consumption.

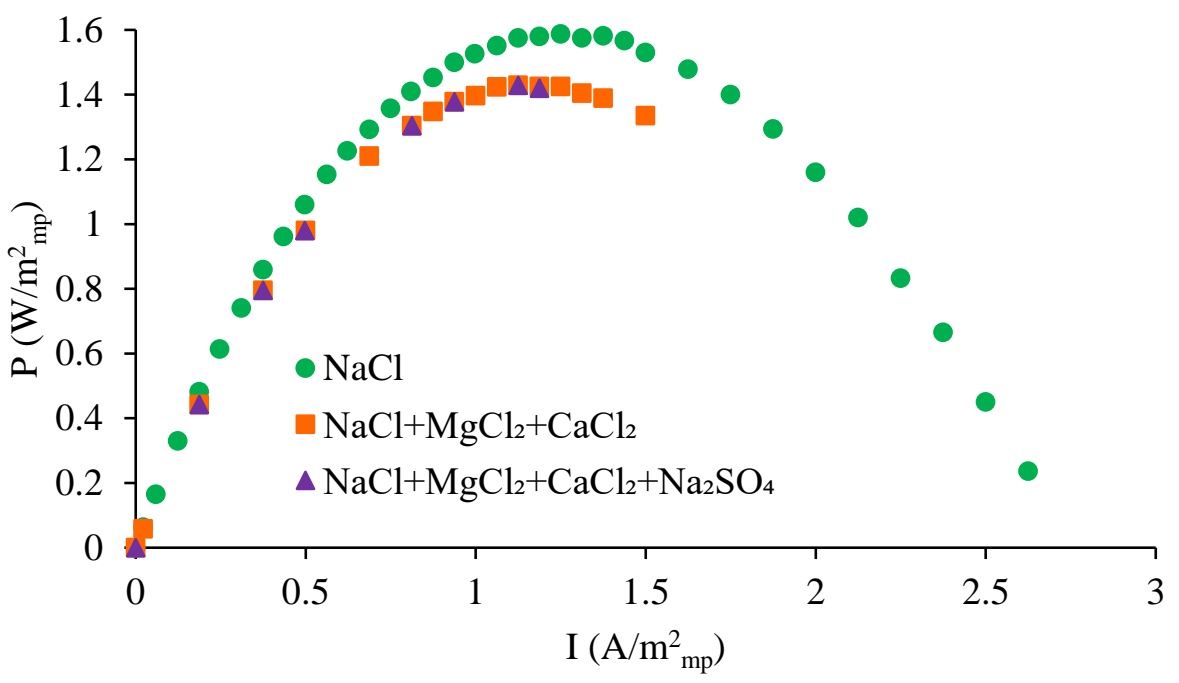

Figure 4. Gross power as function of current density working with model water streams.

Once satisfactory results working with model waters were achieved, the treated real water effluents, SW and RW, were employed as feeding streams for a RED stack to confirm the viability of using a SGE process. The evolution of power output and OCV was monitored over time to study the stability of the RED performance. As representative case, Figure 5 
shows the experimental and simulated power curves after $48 \mathrm{~h}$ of operation and at a fixed temperature of $24^{\circ} \mathrm{C}$. The simulated power curve was calculated with a mathematical model implemented in Aspen Custom Modeler and validated in a previous work [18]. The fitting between experimental and simulated curves, with a difference of $14 \%$ for the points of maximum power output, supports the validity of the model in predicting the RED plant performance. The maximum power output is normalized to the active pair membrane area $\left(36 \mathrm{~cm}^{2}\right)$, and the calculated power density, $1.43 \mathrm{~W} / \mathrm{m}^{2}$, is among the highest values reported for natural and WW streams due to the use of RW [21]. The values achieved were virtually the same as those obtained when model waters were employed (Figure 4). These results demonstrate that real water streams can be effectively employed in RED processes, being necessary to take into account the presence of $\mathrm{MgCl}_{2}$ and $\mathrm{CaCl}_{2}$ in order to quantify the decrease in power performance probably due to an increase in membrane resistance [36,37].

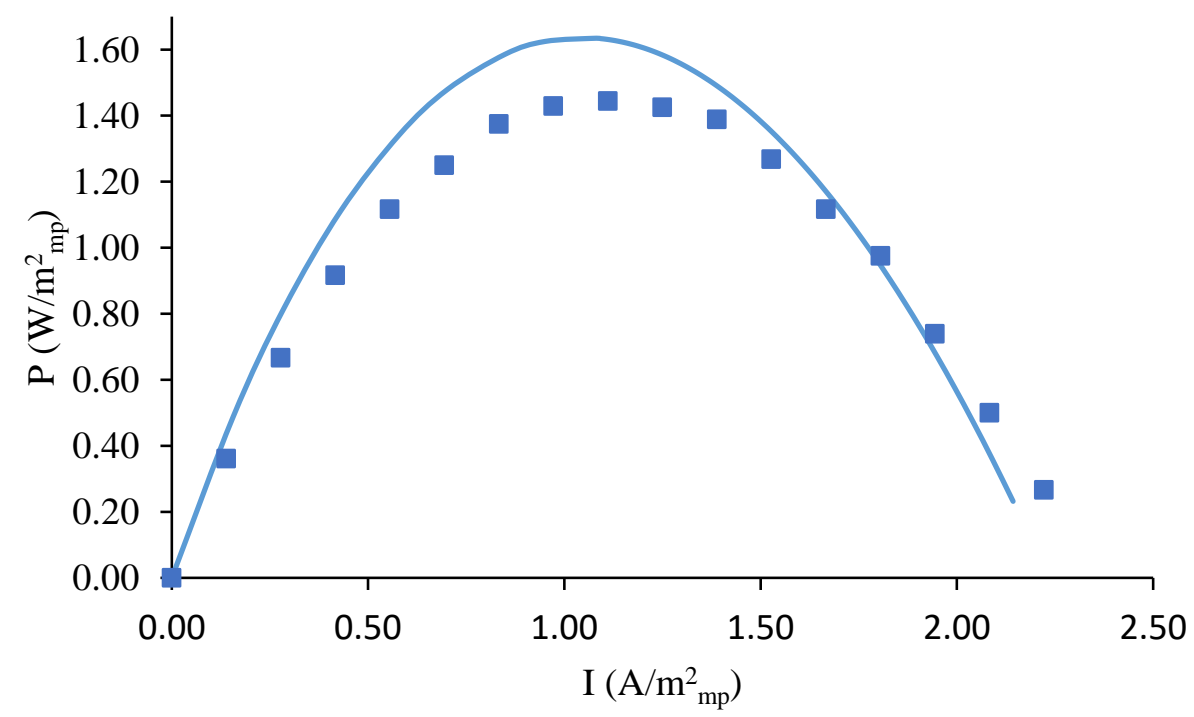

Figure 5. Simulated (continuous line) and experimental (dotted line) of power curves at $48 \mathrm{~h}$.

\subsection{Evaluation of medium-term behaviour of RED system using real water}

The appearance of fouling phenomena on anion and cation exchange membranes in RED systems has been identified as a bottle-neck by previous authors when real scenarios were 
used [25-27,29,33,38]. In this sense, the performance of the tertiary treatment (Figure 1), and a treatment for SW (Figure 2) for fouling prevention in the RED stack is evaluated in this section through the evolution of a SGE- RED process fed with RW and SW treated over the 20 days (480 hours).

Figure 6 shows the power obtained along this period normalized to the value obtained at $48 \mathrm{~h}(100 \%)$, since this is the time at which the system reaches the stationary state. As it can be observed in Figure 6, the response of the system in terms of gross power remains virtually constant for the whole horizon time, with no power performance decay observed. In fact, power performance is always within a $10 \%$ deviation with regard to the value adopted as reference. For the 480 hours, the system was operated continuously with SW and RW, and therefore these results indicate that the reclamation treatment described in Section 2.2 was effective in avoiding the appearance of membrane fouling that otherwise would significantly affect power output, ensuring the smooth running of the stack over time. This finding represents a great progress on this technology, since previous works have reported major fouling issues for the short- and medium-term [25-27], as it will be discussed later.

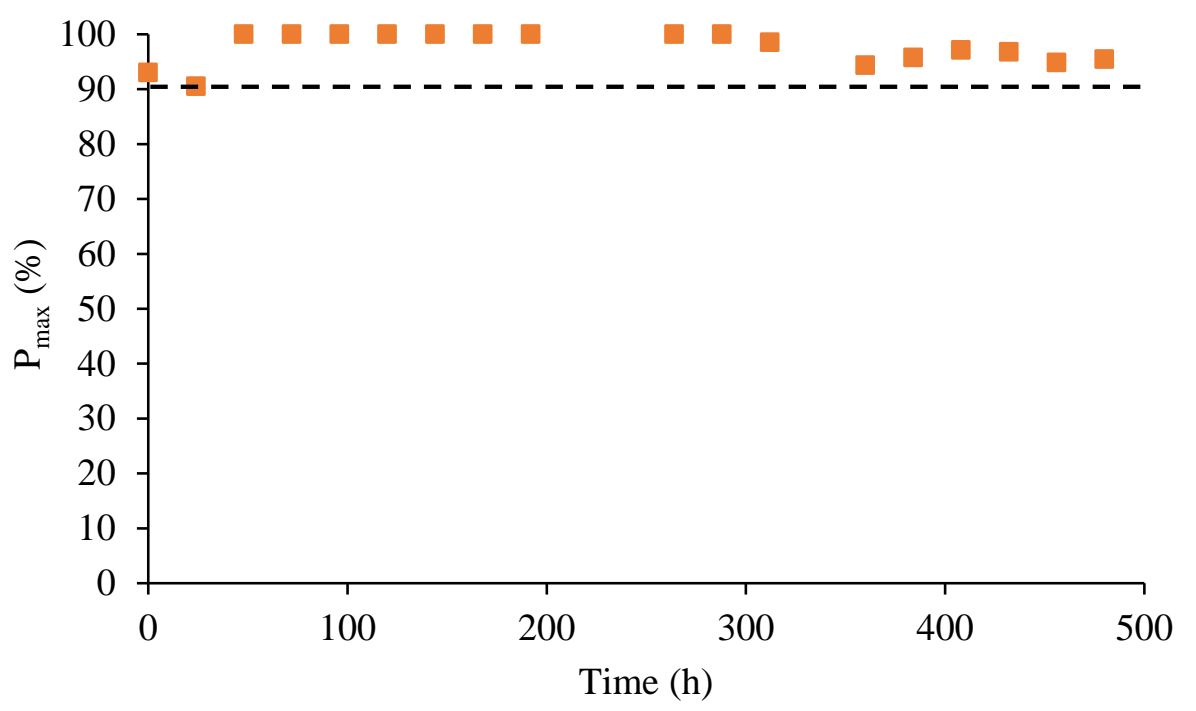

Figure 6. Evolution of normalized power output over time. Dashed line represents $90 \%$.

OCV response was also monitored to study the stability of the RED system performance for the whole time horizon analyzed. Figure 7 shows the measured OCV normalized to the value of OCV reached at $48 \mathrm{~h}$, which corresponds to $3.45 \mathrm{~V}$. As in the case of power performance, the OCV response of the RED system remains almost constant over 480 
hours (with no more than $10 \%$ deviation with respect to the reference value at all times, dashed line), again confirming the effectiveness of the applied treatment to maintain the high performance of the RED stack.

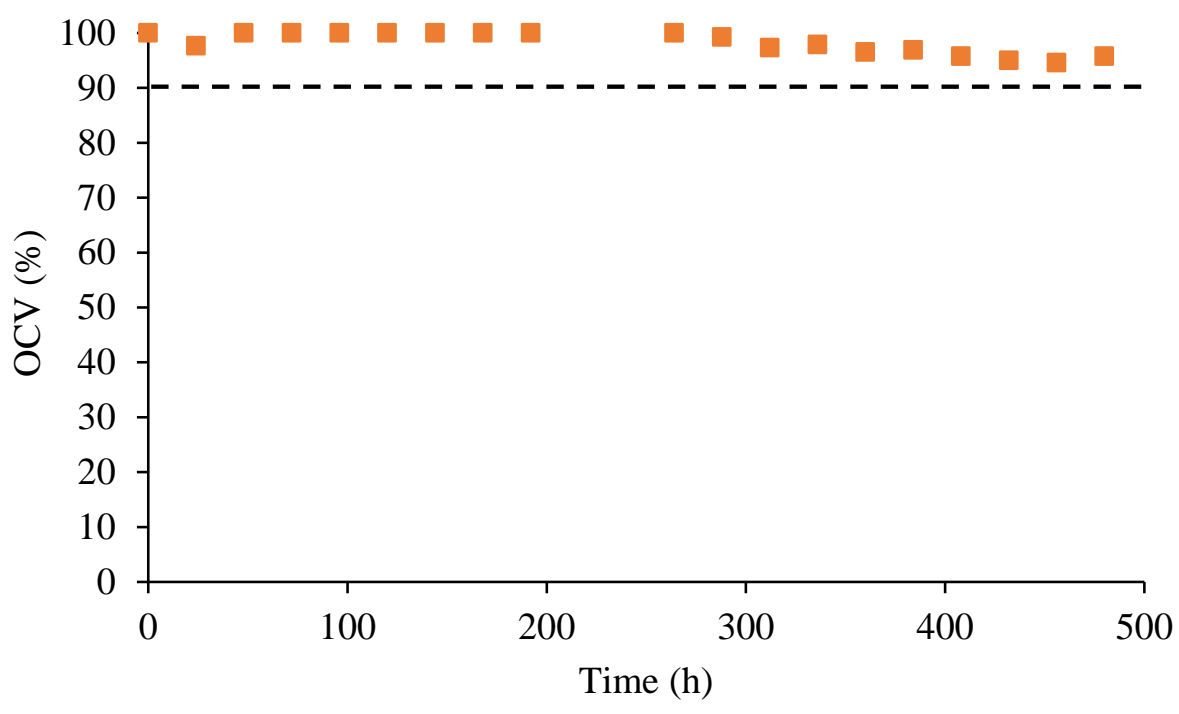

Figure 7. OCV response of the system normalized to the value obtained at $48 \mathrm{~h}$. Dashed line represents $90 \%$.

After the operation time (480 hours), the stack was opened and examined visually to confirm that fouling was avoided using the simple treatment previously described. Figure 8 includes representative photographs of the membranes before and after operation. Specifically, the surface of cation and anion exchange membranes in contact with RW streams are shown. According to the images, membranes offered mostly clean surfaces at the end of the experiment, without observing fouling issues or deposits of blocking materials. The mark visible in Figure $8 \mathrm{~B}$ corresponds to the pressure exerted by the spacers to assembly the membrane. These results were also found for the membrane surfaces in contact with the SW compartments, confirming that the membranes remained in good condition after 480 hours of operation. 
A

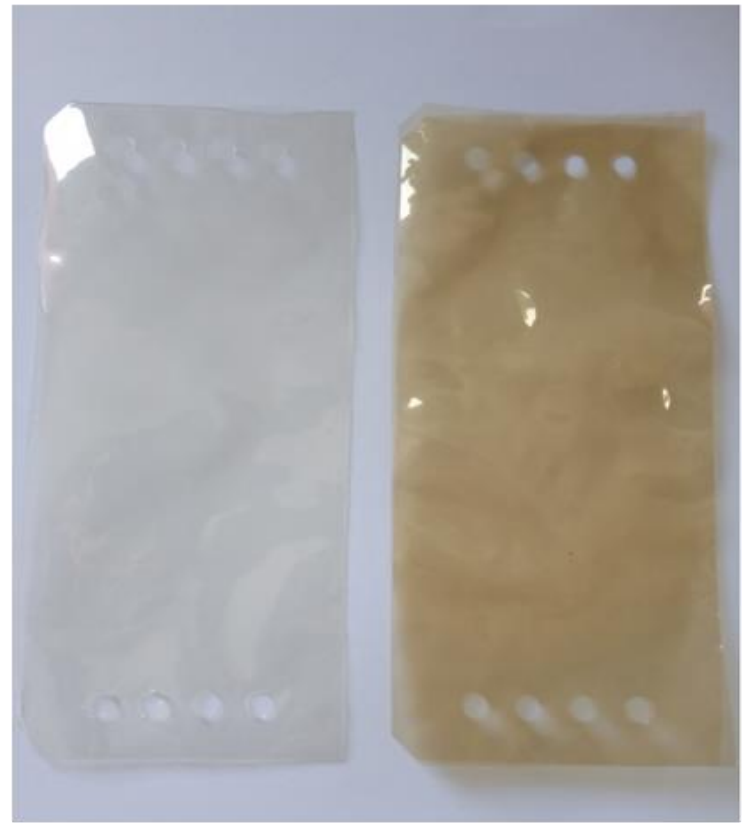

CEM
AEM
B

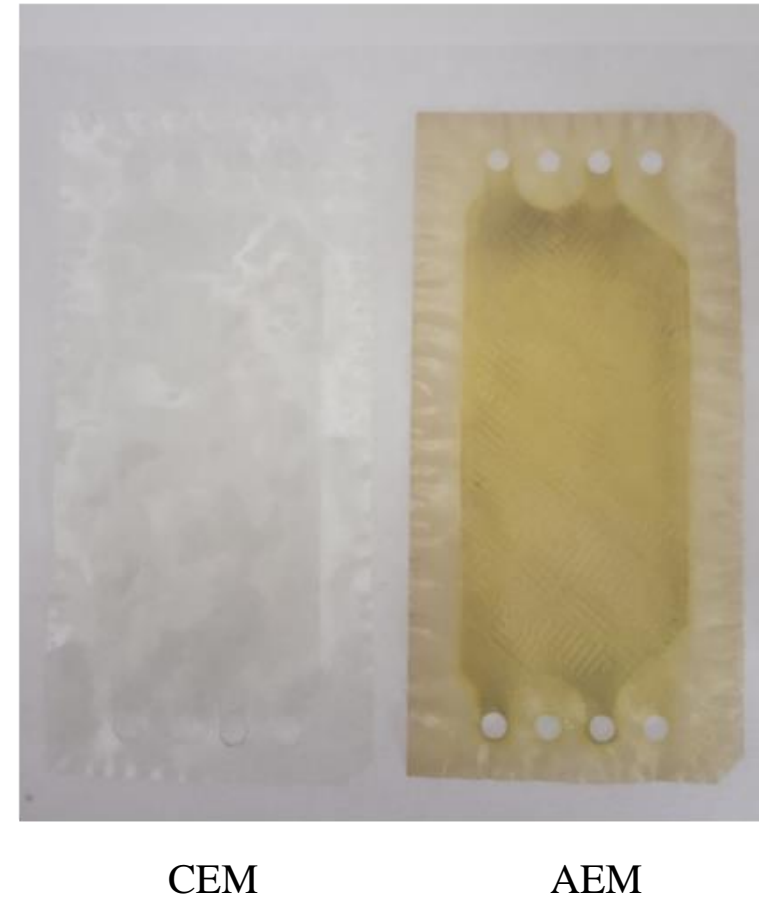

Figure 8. Representative photographs of membranes before (A) and after (B) 480 hours of experiment: anion exchange membrane (AEM), cation exchange membrane (CEM).

The results obtained are very promising since the decay in RED performance related to the appearance of membrane fouling when using natural and WW streams has been frequently reported in the literature for shorter operation times than in this work. Vermaas et al. [26] employed $\mathrm{SW}(0.5 \mathrm{M} \mathrm{NaCl})$ and river water $(0.017 \mathrm{M} \mathrm{NaCl})$ as $\mathrm{HC}$ and $\mathrm{LC}$ solutions, respectively. The water streams were subjected to pre-filtration through several microfilters, with the final filter having a sieve size of $20 \mu \mathrm{m}$. They observed a significant decrease in RED performance after the first day (more than $40 \%$ in terms of normalized power relative to theory) in different stack configuration, including stacks equipped with spacers and with profiled membranes. Di Salvo et al. [27] employed two types of WW to feed RED stacks, fish processing wastewater as $\mathrm{HC}$ solution $(0.5 \mathrm{M} \mathrm{NaCl})$ and reclaimed water from an urban WWTP as LC solution (concentrations between 0.004 and $0.010 \mathrm{M}$ $\mathrm{NaCl}$ ). The fist type of water was treated in a pilot aerobic granular sequence batch airlift reactor system followed by further filtration $(5 \mu \mathrm{m})$, while WWTP effluent was treated in an experimental membrane bioreactor. Fouling issues were detected after 4 days of operation observing a decrease in OCV. Another representative work is that of Moreno et al. [29], who employed real seawater $\left(0.3 \mathrm{M} \mathrm{Na}^{+}\right)$and river water $\left(0.003 \mathrm{M} \mathrm{Na}^{+}\right)$, which were passed through drum filters with an average diameter of $20 \mu \mathrm{m}$. RED performance 
remained well below the scenario in which specific strategies to prevent fouling accumulation during real operation time were applied (e.g. injection of streams saturated with $\mathrm{CO}_{2}$ ). In other work, Moreno et al. [28] studied different types of membranes as well as different quantities of $\mathrm{MgCl}_{2}$ in order to analyse the effect of this compound as substitute of $\mathrm{NaCl}$ in RED performance. Results showed that $\mathrm{MgCl}_{2}$ do not affect the stability of the system. However, a decreased in gross power with respect to the use of pure $\mathrm{NaCl}$ was observed due to the lower ion mobility of magnesium ions inside the membranes. Table 3, summarizes the gross power values reported by these authors when medium- and long-term experiments were carried out [26-29].

Table 3. Gross power values obtained both in this work and literature working during mediumand long-term experiments and divalent ions.

\begin{tabular}{|c|c|c|c|}
\hline Author & Type of water & Gross power $\left(\mathrm{W} / \mathrm{m}^{2}{ }_{\mathrm{mp}}\right)$ & Ref. \\
\hline This work & SW-RW (real water) & 1.4 & - \\
\hline Vermaas et al. & SW-River water (real water) & $\begin{array}{c}0.22-0.28 \text { (profiled membranes) } \\
0.10-0.16 \text { (spacers) }\end{array}$ & {$[26]$} \\
\hline Di Salvo et al. & $\begin{array}{c}\text { Fish wastewater-RW (real water } \\
\text { and model water) }\end{array}$ & $0.60-0.80$ & {$[27]$} \\
\hline Moreno et al. & SW-river water (real water) & $0.10-0.55$ & {$[29]$} \\
\hline Moreno et al. & SW-river water (model water) & $0.40-0.64$ & {$[28]$} \\
\hline
\end{tabular}

In contrast to the results reported in the literature, the treatment applied in this work to both types of water was effective for the medium-run of the system. Specifically, the use of RED units in WWTPs placed on coastal locations offers a great opportunity since SW can be employed as high concentrated solution. On the other hand, the use of RW as feeding solution opens room for a significant exploitation potential. Thus, the results obtained in this manuscript offer a step forward for producing RW with zero energy consumption due to the use of RED technology. Nevertheless, new experiments increasing the temporal horizon may be need to be approached in future research works.

\section{Conclusions}

A novel strategy for water reclamation with simultaneous energy generation from the mixing of RW and SW streams through RED technology has been proposed. After harvesting SGE, the quality of RW achieved met the standards required for multiple uses, in agreement with the policies developed by the European Commission for water reuse. 
The appearance of fouling issues on the anion and cation exchange membranes over a significant time horizon of 480 hours was prevented. For such a period, the operation provided a stable power performance and constant OCV output. The power outcome was validated with a previously developed mathematical model, showing that the maximum power output achieved and maintained over time was very close to the value predicted by the mathematical model $\left(1.43 \mathrm{~W} / \mathrm{m}^{2}\right)$. This strategy would promote wastewater reclamation because the RW with slight increase in salinity in comparison to the WWTP effluent, could be further applied in secondary uses after internal energy recovery. Finally, it is worth noting that RED technology could be directly used in WWTPs equipped tertiary units in order to reduce fossil fuels-based energy consumption.

\section{Acknowledgements}

The authors want to acknowledge financial support from the Community of Cantabria Regional Plan for the project: Gradisal "RM16-XX-046-SODERCAN/FEDER”, as well as the projects funded by the Spanish Ministry of Economy and Competitiveness CTQ2015-66078-R, and CTM2017-87850-R. V.M. Ortiz-Martínez is supported by the Spanish Ministry of Science, Innovation and Universities through the grant 'Juan de la Cierva-Formación’ ref. FJCI-2017-32404).

\section{References}

[1] R.A. Tufa, E. Curcio, E. Brauns, W. van Baak, E. Fontananova, G. Di Profio, Membrane Distillation and Reverse Electrodialysis for Near-Zero Liquid Discharge and low energy seawater desalination, J. Memb. Sci. 496 (2015) 325333. doi:10.1016/j.memsci.2015.09.008.

[2] M. Gündoğdu, N. Kabay, N. Yiğit, M. Kitiş, T. Pek, M. Yüksel, Effect of concentrate recirculation on the product water quality of integrated MBR - NF process for wastewater reclamation and industrial reuse, J. Water Process Eng. 29 (2019) 100485. doi:10.1016/j.jwpe.2017.08.023.

[3] M. Mukherjee, O. Jensen, Making water reuse safe: A comparative analysis of the development of regulation and technology uptake in the US and Australia, Saf. Sci. 121 (2020) 5-14. doi:10.1016/j.ssci.2019.08.039.

[4] T. Alemu, A. Mekonnen, S. Leta, Integrated tannery wastewater treatment for effluent reuse for irrigation: Encouraging water efficiency and sustainable 
development in developing countries, J. Water Process Eng. 30 (2019) 100514. doi:10.1016/j.jwpe.2017.10.014.

[5] M. Vojtěchovská Šrámková, V. Diaz-Sosa, J. Wanner, Experimental verification of tertiary treatment process in achieving effluent quality required by wastewater reuse standards, J. Water Process Eng. 22 (2018) 41-45. doi:10.1016/j.jwpe.2018.01.003.

[6] UN-WATER, Wastewater - The Untapped Resources, 2017. doi:10.1017/CBO9781107415324.004.

[7] I. Ortiz, A. Mosquera-Corral, J. Lema, A. Espuglas, Advanced Technologies for Water Treatment and Reuse, AIChE J. 61 (2015) 857-866. doi:10.1002/aic.

[8] EU Water Framework Directive 2000/60/EC, DIRECTIVE 2000/60/EC OF THE EUROPEAN PARLIAMENT AND OF THE COUNCIL of 23 October 2000 establishing a framework for Community action in the field of water policy, Off. J. Eur. Commun. (2017). doi:10.1039/ap9842100196.

[9] Council of the European Communities, Urban Waste Water Treatment Directive, Off. J. Eur. Union. (1991) 40-52. http://eur-lex.europa.eu/legalcontent/EN/TXT/PDF/?uri=CELEX:31991L0271\&from=EN.

[10] E. Comission, Proposal for a REGULATION OF THE EUROPEAN PARLIAMENT AND OF THE COUNCIL on minimum requirements for water reuse (Text with EEA relevance) (accessed July 26, 2019).

[11] Council of the European Union, Council Directive 91/271/EEC of 21 May 1991 concerning urban waste-water treatment, 1991. http://data.europa.eu/eli/dir/1991/271/oj.

[12] Enerwater - Waste water treatment Plants Project, (n.d.). http://www.enerwater.eu/enerwater-project-waste-water-treatment-plants/ (accessed May 20, 2019).

[13] A.K. Plappally, J.H. Lienhard V, Energy requirements for water production, treatment, end use, reclamation, and disposal, Renew. Sustain. Energy Rev. (2012). doi:10.1016/j.rser.2012.05.022.

[14] M.W. Shahzad, M. Burhan, L. Ang, K.C. Ng, Energy-water-environment nexus underpinning future desalination sustainability, Desalination. 413 (2017) 52-64. doi:10.1016/j.desal.2017.03.009.

[15] B.E. Logan, M. Elimelech, Membrane-based processes for sustainable power generation using water, Nature. 488 (2012) 313-319. doi:10.1038/nature11477.

[16] J.W. Post, J. Veerman, H.V.M. Hamelers, G.J.W. Euverink, S.J. Metz, K. Nymeijer, C.J.N. Buisman, Salinity-gradient power: Evaluation of pressureretarded osmosis and reverse electrodialysis, J. Memb. Sci. 288 (2007) 218-230. doi:10.1016/j.memsci.2006.11.018.

[17] A. Altaee, J. Zhou, G. Zaragoza, A.O. Sharif, Impact of membrane orientation on the energy efficiency of dual stage pressure retarded osmosis, J. Water Process Eng. 30 (2019) 100621. doi:10.1016/j.jwpe.2018.05.001.

[18] R. Ortiz-imedio, L. Gomez-coma, M. Fallanza, A. Ortiz, R. Ibañez, I. Ortiz, 
Comparative performance of Salinity Gradient Power-Reverse Electrodialysis under different operating conditions, Desalination. 457 (2019) 8-21. doi:10.1016/j.desal.2019.01.005.

[19] J.W. Post, C.H. Goeting, J. Valk, S. Goinga, J. Veerman, H.V.M. Hamelers, P.J.F.M. Hack, Towards implementation of reverse electrodialysis for power generation from salinity gradients, Desalin. Water Treat. 16 (2010) 182-193. doi:10.5004/dwt.2010.1093.

[20] J.W. Post, Blue Energy: electricity production from salinity gradients by reverse electrodialysis (PhD Thesis), Wageningen University, 2009.

[21] R.A. Tufa, S. Pawlowski, J. Veerman, K. Bouzek, E. Fontananova, G. di Profio, S. Velizarov, J. Goulão Crespo, K. Nijmeijer, E. Curcio, Progress and prospects in reverse electrodialysis for salinity gradient energy conversion and storage, Appl. Energy. 225 (2018) 290-331. doi:10.1016/j.apenergy.2018.04.111.

[22] Y. Oh, Y. Jeong, S.J. Han, C.S. Kim, H. Kim, J.H. Han, K.S. Hwang, N. Jeong, J.S. Park, S. Chae, Effects of Divalent Cations on Electrical Membrane Resistance in Reverse Electrodialysis for Salinity Power Generation, Ind. Eng. Chem. Res. 57 (2018) 15803-15810. doi:10.1021/acs.iecr.8b03513.

[23] A.H. Avci, P. Sarkar, R.A. Tufa, D. Messana, P. Argurio, E. Fontananova, G. Di Profio, E. Curcio, Effect of $\mathrm{Mg} 2+$ ions on energy generation by Reverse Electrodialysis, J. Memb. Sci. 520 (2016) 499-506. doi:10.1016/j.memsci.2016.08.007.

[24] T. Rijnaarts, E. Huerta, W. van Baak, K. Nijmeijer, Effect of Divalent Cations on RED Performance and Cation Exchange Membrane Selection to Enhance Power Densities, Environ. Sci. Technol. (2017) acs.est.7b03858. doi:10.1021/acs.est.7b03858.

[25] D.A. Vermaas, D. Kunteng, J. Veerman, M. Saakes, K. Nijmeijer, Periodic feedwater reversal and air sparging as antifouling strategies in reverse electrodialysis, Environ. Sci. Technol. 48 (2014) 3065-3073. doi:10.1021/es4045456.

[26] D.A. Vermaas, D. Kunteng, M. Saakes, K. Nijmeijer, Fouling in reverse electrodialysis under natural conditions, Water Res. 47 (2013) 1289-1298. doi:10.1016/j.watres.2012.11.053.

[27] J. Luque Di Salvo, A. Cosenza, A. Tamburini, G. Micale, A. Cipollina, Long-run operation of a reverse electrodialysis system fed with wastewaters, J. Environ. Manage. 217 (2018) 871-887. doi:10.1016/j.jenvman.2018.03.110.

[28] J. Moreno, V. Díez, M. Saakes, K. Nijmeijer, Mitigation of the effects of multivalent ion transport in reverse electrodialysis, J. Memb. Sci. 550 (2018) 155162. doi:10.1016/j.memsci.2017.12.069.

[29] J. Moreno, N. de Hart, M. Saakes, K. Nijmeijer, CO2 saturated water as two-phase flow for fouling control in reverse electrodialysis, Water Res. (2017). doi:10.1016/j.watres.2017.08.015.

[30] A.M. Urtiaga, G. Pérez, R. Ibáñez, I. Ortiz, Removal of pharmaceuticals from a WWTP secondary effluent by ultrafiltration/reverse osmosis followed by 
electrochemical oxidation of the RO concentrate, Desalination. 331 (2013) 26-34. doi:10.1016/j.desal.2013.10.010.

[31] M. Vanoppen, T. van Vooren, L. Gutierrez, M. Roman, L.J.P. Croué, K. Verbeken, J. Philips, A.R.D. Verliefde, Secondary treated domestic wastewater in reverse electrodialysis: What is the best pre-treatment?, Sep. Purif. Technol. 218 (2019) 25-42. doi:10.1016/j.seppur.2018.12.057.

[32] M. Vaselbehagh, H. Karkhanechi, R. Takagi, H. Matsuyama, Biofouling phenomena on anion exchange membranes under the reverse electrodialysis process, J. Memb. Sci. 530 (2017) 232-239. doi:10.1016/j.memsci.2017.02.036.

[33] R.S. Kingsbury, F. Liu, S. Zhu, C. Boggs, M.D. Armstrong, D.F. Call, O. Coronell, Impact of natural organic matter and inorganic solutes on energy recovery from five real salinity gradients using reverse electrodialysis, J. Memb. Sci. 541 (2017) 621-632. doi:10.1016/j.memsci.2017.07.038.

[34] Y. Mei, C.Y. Tang, Recent developments and future perspectives of reverse electrodialysis technology: A review, Desalination. 425 (2017) 156-174. doi:10.1016/j.desal.2017.10.021.

[35] Ministerio de España. Spanish Goverment, REAL DECRETO 1620/2007, de 7 de diciembre, por el que se establece el régimen jurídico de la reutilización de las aguas depuradas (2007) 16100-16111.

[36] A.H. Galama, N.A. Hoog, D.R. Yntema, Method for determining ion exchange membrane resistance for electrodialysis systems, Desalination. 380 (2016) 1-11. doi:10.1016/j.desal.2015.11.018.

[37] A.H. Avci, P. Sarkar, R.A. Tufa, D. Messana, P. Argurio, E. Fontananova, G. Di Profio, E. Curcio, Effect of $\mathrm{Mg} 2+$ ions on energy generation by Reverse

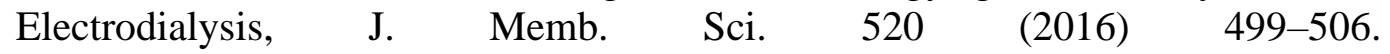
doi:10.1016/j.memsci.2016.08.007.

[38] M. Tedesco, C. Scalici, D. Vaccari, A. Cipollina, A. Tamburini, G. Micale, Performance of the first reverse electrodialysis pilot plant for power production from saline waters and concentrated brines, J. Memb. Sci. 500 (2016) 33-45. doi:10.1016/j.memsci.2015.10.057. 